\title{
Microwave-induced, solvent-free transformations of benzoheteracyclanones by HTIB (Koser's reagent)
}

\author{
Tamás Patonay*,a , Albert Lévai ${ }^{a}$, Éva Rimán ${ }^{a}$, and Rajender S. Varma \\ ${ }^{a}$ Department of Organic Chemistry, University of Debrecen, H-4010 Debrecen, P.O. Box 20, \\ Hungary \\ E-mail: tpatonay@tigris.unideb.hu \\ ${ }^{b}$ National Risk Management Research Laboratory, US Environmental Protection Agency, \\ MS 443 Cincinnati OH 45268, USA
}

\section{Dedicated to Professor Sándor Antus on the occasion of his $60^{\text {th }}$ birthday}

(received 15 Jan 04; accepted 06 Apr 04; published on the web 07 Apr 04)

\begin{abstract}
The microwave-activated reactions of [hydroxy(tosyloxy)iodo]benzene (HTIB) with various chromanones, thiochromanones and dihydroquinolones under solvent-free conditions have been studied. In addition to the common dehydrogenation reaction, 2,3-migration also has been observed in the case of flavanone and 2,2-disubstituted chromanones. 3-Tosyloxychromanones were isolated from the reaction of chromanone and 2-methylchromanone for the first time. Substrates with nucleophilic heteroatoms such as thiochromanones and 2-phenyl-2,3-dihydro-4quinolone reacted by electrophilic attack of the heteroatom.
\end{abstract}

Keywords: Chromanones, 2,3-dihydro-4-quinolones, hypervalent iodine reagent, microwave irradiation, thiochromanones, tosyloxylation

\section{Introduction}

[Hydroxy(tosyloxy)iodo]benzene ${ }^{1}$ (HTIB, Koser's reagent) and related hypervalent iodine derivatives have become widely used reagents for synthetic organic chemistry during the last decades, and excellent overviews of their chemistry have been forthcoming in several papers. ${ }^{2}$ The most frequently exploited reactions of HTIB and the other [(arylsulfonyloxy)(hydroxy)iodo]benzene analogues are the $\alpha$-sulfonyloxylation of ketones (or their enol derivatives), sulfonyloxylation of double bonds, phenyliodination and oxidation, and all of these approaches have been utilized in the synthesis of various heterocyclic systems ${ }^{2}$. A survey of the literature reveals continuous efforts to develop these reagents and the conditions for their use. Some recent examples are preparation of isoflavones from 2'-hydroxychalcones by 
means of a polymer-supported reagent, ${ }^{3} \alpha$-tosyloxylation in ionic liquids, ${ }^{4} \alpha$-hydroxylation of ketones by HTIB in DMSO-water mixtures, ${ }^{5}$ oxidative $\alpha$-tosyloxylation of alcohols into $\alpha$ tosyloxy aldehydes and ketones ${ }^{6}$ or the use of [hydroxy(2,4dinitrobenzenesulfonyloxy)iodo]benzene (HDNIB) ${ }^{7}$

Microwave (MW) irradiation is an efficient and environmentally-benign method to activate various organic transformations to afford products in higher yields in shorter reaction periods. In this class of MW-assisted reactions, solvent-free syntheses are of particular interest and importance in view of their simplicity, tunability and ease of work-up. ${ }^{8} \mathrm{MW}$ activation was utilized advantageously in the $\alpha$-tosyloxylation of acetophenones by HTIB in the presence of K10 clay and the generated tosylates were successfully transformed into thiazoles and imidazo[2,1-b]thiazoles. ${ }^{9}$

In continuation of our studies in the field of cyclic $\alpha$-(arylsulfonyloxy)ketones and oxygencontaining heterocycles, we decided to investigate the reaction of various chromanone derivatives and their sulfur or nitrogen-containing analogues with HTIB under MW irradiation and solvent-free conditions, and the most characteristic results are presented here.

\section{Results and Discussion}

First, we searched for the most efficient MW-inactive support for use of the highly sensitive 2,2dimethyl-7-methoxychromanone (5b) as a test molecule. MW irradiation and subsequent workup afforded the expected 2,3-dimethyl-7-methoxychromone (6b) in addition to some unidentified, highly polar products which could be removed easily by filtration through a short pad of silica or by short-column chromatography (Scheme 1, Table 1). The structure of the product was in accordance with literature data, Prakash and his coworkers ${ }^{10}$ have observed the same 2,3-methyl migration and dehydrogenation in refluxing acetonitrile using ultrasound activation.

Table 1. Effect of the support on the MW-induced reaction of 2,2-dimethyl-7-methoxychromanone (5b) with HTIB $^{\mathrm{a}}$

\begin{tabular}{ccccc}
\hline Entry & Support & MW Irradiation (min) & Conversion $^{\mathrm{b}}(\%)$ & Yield $^{\mathrm{c}}(\%)$ \\
\hline 1 & None & $4 \times 1$ & 80 & 41 \\
2 & Montmorillonite K-10 & $20 \times 1$ & 29 & 46 \\
3 & $\mathrm{Al}_{2} \mathrm{O}_{3}$ (neutral) & $20 \times 1+15 \times 2$ & 57 & 53 \\
4 & $\mathrm{CaCO}_{3}$ & $20 \times 1+5 \times 2$ & 80 & 59 \\
5 & $\mathrm{Na}_{2} \mathrm{SO}_{4}$ & $12 \times 1$ & 88 & 61 \\
\hline
\end{tabular}

${ }^{a}$ According to the General Procedure (Experimental Part) by treating $1.00 \mathrm{mmol}$ of $5 \mathbf{b}$ with $1.20 \mathrm{mmol}$ of HTIB, elution with hexane-ethyl acetate $(1: 1, \mathrm{v} / \mathrm{v}) .{ }^{\mathrm{b}}$ Calculated on the basis of the recovered starting material. ${ }^{\mathrm{c}}$ Refers to pure isolated products, the values are normalized to $100 \%$ conversion. 
The results summarized in Table 1 reveal a decisive role for the support. Surprisingly, poor conversion and low yield was found using Montmorillonite K10 and neutral alumina. Inorganic salts such as $\mathrm{CaCO}_{3}$ or $\mathrm{Na}_{2} \mathrm{SO}_{4}$ gave much better conversions. Good conversions also have been achieved without any support, but the yield was lower due to secondary reactions causing the decomposition of the product. Taking the length of the irradiation period, conversions and yields into consideration, we chose $\mathrm{Na}_{2} \mathrm{SO}_{4}$ as the carrier for further experiments.<smiles></smiles>

\begin{tabular}{c|ccc} 
1-4 & a & b & c \\
\hline $\mathrm{R}$ & $\mathrm{H}$ & $\mathrm{Me}$ & $\mathrm{Ph}$
\end{tabular}<smiles>[R]c1cc2c(c([R])c1[R])C(=O)CC(C)(C)O2</smiles>

5a-c,e-g<smiles>[R]c1cc2oc(C)c(C)c(=O)c2c([R])c1[R]</smiles>

6a-c,e-g<smiles>[R]c1coc2ccccc2c1=O</smiles>

4

\begin{tabular}{c|ccccccc}
$\mathbf{5 , 6}$ & $\mathbf{a}$ & $\mathbf{b}$ & $\mathbf{c}$ & $\mathbf{d}$ & $\mathbf{e}$ & $\mathbf{f}$ & $\mathbf{g}$ \\
\hline $\mathrm{R}^{1}$ & $\mathrm{H}$ & OMe & OBn & OH & OTs & OTs & OBn \\
$\mathrm{R}^{2}$ & $\mathrm{H}$ & $\mathrm{H}$ & $\mathrm{H}$ & $\mathrm{H}$ & $\mathrm{H}$ & OTs & $\mathrm{H}$ \\
$\mathrm{R}^{3}$ & $\mathrm{H}$ & $\mathrm{H}$ & $\mathrm{H}$ & $\mathrm{H}$ & $\mathrm{H}$ & $\mathrm{H}$ & $\mathrm{Me}$
\end{tabular}<smiles>O=C1CC2(CCCC2)Oc2ccccc21</smiles>

8a-c

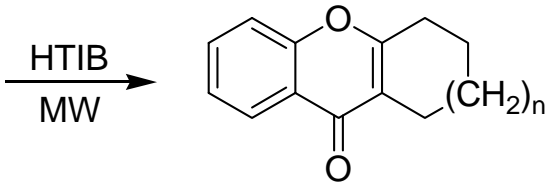

9a-c<smiles>O=C1c2ccccc2OC2(CCCC2)C1[O-]</smiles>

10

$$
\begin{array}{c|ccc}
\mathbf{8 , 9} & \mathbf{a} & \mathbf{b} & \mathbf{c} \\
\hline \mathrm{n} & 1 & 2 & 3
\end{array}
$$

\section{Scheme 1}

The reactions of chromanone (1a) and 2-methylchromanone (1b) afforded a mixture of the 3tosyloxychromanones 2a,b and the corresponding chromones $\mathbf{3 a}, \mathbf{b}$ under the optimized conditions (Table 2, Scheme 1). It was noteworthy that, in the case of $\mathbf{1 b}$ the oxidative 
sulfonyloxylation took place with complete diastereoselectivity; only the cis diastereomer could be detected and isolated. The relative configuration of the obtained cis-2-methyl-3tosyloxychromanone (2b) has been determined on the basis of the small value for the ${ }^{3} J_{2 H, 3 H}$ coupling constant $(3.7 \mathrm{~Hz})$. Earlier, Liebscher and coworkers have reported values of ${ }^{3} J_{2 H, 3 H}=$ $12.4 \mathrm{~Hz}$ for trans-3-hydroxy-2-propylchromanone and ${ }^{3} J_{2 \mathrm{H}, 3 \mathrm{H}}=6.0 \mathrm{~Hz}$ for cis-3-hydroxy-2methylchromanone. The stereochemistry of the cis-3-hydroxy-2-methyl-2,3-dihydro-4Hnaphto[2,3-b]pyran-4-one also has been proven by X-ray crystallography. ${ }^{11}$ In spite of the low yields of tosylates 2a,b, the method has some synthetic value since 3arylsulfonyloxychromanones were practically unknown. The only exception, 3-[(4nitrobenzenesulfonyl)oxy]chromanone, was obtained from 4-acetoxy- $2 \mathrm{H}$-1-chromene with bis(4nitrobenzenesulfonyl) peroxide. ${ }^{12}$ Further, no tosylates 2a,b have been isolated previously from the reaction of substrates 1a,b and HTIB in hot acetonitrile with or without sonication, ${ }^{10}$ proving again the beneficial effect of MW irradiation.

On the contrary, when flavanone (1c) was treated with HTIB no tosylate 2c was obtained and the reaction yielded a mixture of flavone (3c) and isoflavone (4c) (Table 2, Scheme 1). This result is in accordance with the literature data. According to Prakash et al., 3-tosyloxyflavanone was never observed using classical heating and the product ratio depended strongly on the conditions. In boiling acetonitrile or propionitrile, isoflavone (4c) was the major product accompanied with a small amount of flavone (3c) and methyl 2-phenyl-2,3-dihydrobenzofuran3 -carboxylate. ${ }^{13}$ The change of the solvent to methanol resulted in a dramatic shift as flavone (3c) became the major product, accompanied by some cis-3-methoxyflavanone and methyl 2phenyl-2,3-dihydrobenzofuran-3-carboxylate. ${ }^{14}$ The oxidative rearrangement of flavanone (1c) also has been performed using other reagents such as iodobenzene diacetate/ $p$-toluenesulfonic acid in acetonitrile, iodosobenzene/methanesulfonic acid in methylene chloride or acetonitrile ${ }^{2}$ or various thallium(III) reagents. ${ }^{15}$

Table 2. Reaction of chromanones 1a-c with HTIB under MW irradiation using $\mathrm{Na}_{2} \mathrm{SO}_{4}$ support

\begin{tabular}{|c|c|c|c|c|c|c|c|c|}
\hline \multirow[t]{2}{*}{ Entry } & \multirow{2}{*}{$\begin{array}{l}\text { Starting } \\
\text { material }\end{array}$} & \multirow{2}{*}{$\begin{array}{l}\text { HTIB } \\
\text { (equiv.) }\end{array}$} & \multirow{2}{*}{$\begin{array}{l}\text { MW irradiation } \\
(\min )\end{array}$} & \multirow[t]{2}{*}{ Eluent $^{\mathrm{a}}$} & \multirow{2}{*}{$\begin{array}{c}\text { Conversion }^{\mathrm{b}} \\
(\%)\end{array}$} & \multicolumn{3}{|c|}{ Yield $^{\mathrm{c}}(\%)$} \\
\hline & & & & & & 2 & 3 & 4 \\
\hline 1 & 1a & 1.2 & $6 \times 1$ & A & 70 & 6.1 & 45 & 0 \\
\hline 2 & & 2.4 & $8 \times 1$ & B & 63 & 12 & 62 & 0 \\
\hline 3 & $1 b$ & 1.2 & $3 \times 1$ & B & 85 & 32 & 28 & 0 \\
\hline 4 & & 2.4 & $3 \times 1$ & B & 100 & 25 & 19 & 0 \\
\hline 5 & 1c & 1.2 & $4 \times 1$ & A & 100 & 0 & 25 & 20 \\
\hline 6 & & 2.4 & $2 \times 1$ & B & 95 & 0 & 13 & 47 \\
\hline
\end{tabular}

${ }^{a} A$ : dichloromethane, $B$ : dichloromethane, components of low $\mathrm{R}_{\mathrm{f}}$ were eluted by ethyl acetate and re-chromatographed using hexane-ethyl acetate $(1: 1, \mathrm{v} / \mathrm{v})$.

${ }^{\mathrm{b}}$ Calculated on the basis of the recovered starting material. ${ }^{\mathrm{c}}$ Refers to pure isolated products, the values are normalized to $100 \%$ conversion. 
The treatment of various substituted 2,2-dimethylchromanones 5a-c,e-g with HTIB under our MW conditions afforded the corresponding 2,3-dimethylchromones 6a-c,e-g (Table 3, Scheme 1). The use of higher amounts of HTIB resulted in an increase in the conversion in all cases, but the yields were significantly lower due to the decomposition of the primary products formed. This tendency is quite conspicuous in the case of 7-benzyloxy-2,2,5-trimethylchromanone (5g) where the aromatic ring is highly activated and, therefore, sensitive to the competitive attack of the electrophilic reagent (Table 3, Entries 9,10). For the same reason, the reaction of 2,2dimethyl-7-hydroxychromanone (5d) failed to give any desired rearranged product $\mathbf{6 d}$. The latter was prepared by the acid-catalyzed debenzylation of the protected derivative $\mathbf{6 c}$.

Table 3. Reaction of 2,2-disubstituted chromanones 5a-c,e-g, 8a-c with HTIB under MW irradiation using $\mathrm{Na}_{2} \mathrm{SO}_{4}$ support

\begin{tabular}{|c|c|c|c|c|c|c|c|}
\hline Entry & $\begin{array}{l}\text { Starting } \\
\text { material }\end{array}$ & $\begin{array}{l}\text { HTIB } \\
\text { (equiv.) }\end{array}$ & $\begin{array}{l}\text { MW irradiation } \\
(\mathrm{min})\end{array}$ & Eluent $^{\mathrm{a}}$ & $\begin{array}{c}\text { Conversion }{ }^{\mathrm{b}} \\
(\%)\end{array}$ & Product & $\begin{array}{c}\text { Yield }^{\mathrm{c}} \\
(\%)\end{array}$ \\
\hline 1 & $5 a$ & 1.2 & $8 \times 1$ & $\mathrm{~A}$ & 64 & $6 a$ & 85 \\
\hline 2 & & 2.4 & $6 \times 1$ & $\mathrm{C}$ & 100 & & 78 \\
\hline 3 & $5 b$ & 1.2 & $6 \times 1$ & $\mathrm{C}$ & 65 & $6 b$ & 60 \\
\hline 4 & & 2.4 & $6 \times 1$ & $\mathrm{C}$ & 89 & & 37 \\
\hline 5 & $5 c$ & 1.2 & $5 \times 1$ & $\mathrm{D}$ & 80 & $6 c$ & 80 \\
\hline 6 & $5 e$ & 1.2 & $6 \times 1$ & $\mathrm{C}$ & 81 & $6 e$ & 85 \\
\hline 7 & $5 f$ & 1.2 & $6 \times 1$ & A & 52 & $6 f$ & 84 \\
\hline 8 & & 2.4 & $6 \times 1$ & $\mathrm{C}$ & 93 & & 71 \\
\hline 9 & $5 g$ & 1.2 & $8 \times 1$ & $\mathrm{D}$ & 64 & $6 g$ & 28 \\
\hline 10 & & 2.4 & $6 \times 1$ & $\mathrm{D}$ & 92 & & 3.7 \\
\hline 11 & $8 a$ & 1.2 & $6 \times 1$ & $\mathrm{D}$ & 82 & $9 a$ & 82 \\
\hline 12 & & 2.4 & $6 \times 1$ & $\mathrm{D}$ & 100 & & 73 \\
\hline 13 & $8 b$ & 1.2 & $3 \times 1$ & A & 75 & $9 b$ & 97 \\
\hline 14 & & 2.4 & $2 \times 1$ & A & 100 & & 76 \\
\hline 15 & $8 c$ & 1.2 & $4 \times 1$ & $\mathrm{D}$ & 63 & 9c & 80 \\
\hline 16 & & 2.4 & $2 \times 1$ & $\mathrm{D}$ & 100 & & 57 \\
\hline
\end{tabular}

${ }^{a}$ A: dichloromethane, C: dichloromethane-acetone (10:1, v/v), D: 1,2-dichloroethane.

${ }^{\mathrm{b}}$ Calculated on the basis of the recovered starting material. ${ }^{\mathrm{c}}$ Refers to pure isolated products, the values are normalized to $100 \%$ conversion.

The 2,3-alkyl migration and dehydrogenation also was observed in the reaction of the 2spirochromanones 8a-c to give the corresponding tricyclic products 9a-c in good-to-excellent yields. The same reaction had been observed previously from the treatment of the spirochromanones with HTIB in hot acetonitrile, with or without ultrasound activation, ${ }^{10}$ or with thallium(III) trinitrate in hot acetonitrile. ${ }^{16}$ Based on the results, we can conclude that the 
rearrangement is expected only with 2,2-disubstituted chromanones or 2-substituted chromanones containing a group of high migrating capability (e.g. aryl). HTIB-induced dehydrogenation and migration of spirochromanones offers a useful method for the synthesis of various naturally-occurring and/or biologically active targets and some such molecules containing a tetrahydroxanthone moiety are shown in Figure 1. To the best of our knowledge, the only exploitation of this approach has been presented by Gabutt et al. ${ }^{21}$ who accomplished the synthesis of the rotenoid core.<smiles>CC1(O)c2c(oc3cc(O)cc(O)c3c2=O)C(O)C(O)C1O</smiles>

Aphloiol $^{17}$<smiles>C=C(C)C1CC(=O)c2oc3c4c(cc(O)c3c(=O)c2C1)OC(C)(C)C=C4</smiles>

Artonol $\mathrm{A}^{20}$<smiles>[R]C1CCC(O)c2oc3cc(OC)cc(O)c3c(=O)c21</smiles>

$\mathrm{R}=\mathrm{H}, \beta-D-\mathrm{Glu}$

Tetrahydroswertianolin ${ }^{18}$<smiles>CC(=O)c1c2c(cc3c(=O)c4c(O)cc5c(c4oc13)C=CC(C)(C)O5)C(=O)OC2(C)C</smiles>

Artonol B ${ }^{20}$<smiles>CC(C)=CCc1c(O)cc2oc3c(c(=O)c2c1O)C(CC=C(C)C)(CC=C(C)C)C(=O)CC3</smiles>

zeyloxanthonone $=$ wightianone $^{19}$

\section{Figure 1}

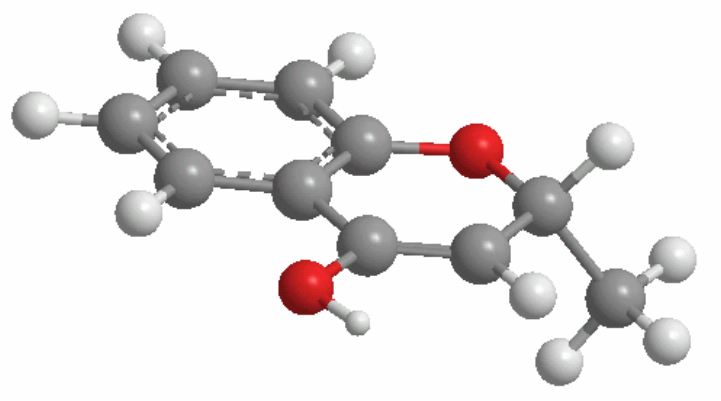

\section{Figure 2}

The obtained results can be integrated in a single mechanism. According to the literature, ${ }^{2}$ the reacting species in the HTIB-mediated reactions is the 3-phenyliodonio intermediate 11 which has a trans relative configuration in the case of 2-substituted chromanones. The preferred formation of this diastereomer can be rationalized in terms of the optimized ${ }^{22}$ conformation of the enol of the chromanone (see Figure 2) which allows attack of the HTIB only from the opposite side. $\mathrm{S}_{\mathrm{N}} 2$ attack of the tosylate anion results in the stereoselective formation of chromanone 2 (arrow (a), Scheme 2) while the migration of the antiperiplanar alkyl or alkylene group by the loss of iodobenzene (arrow (b), Scheme 2) results in the formation of the resonance-stabilized cation $\mathbf{1 2 b}$. 


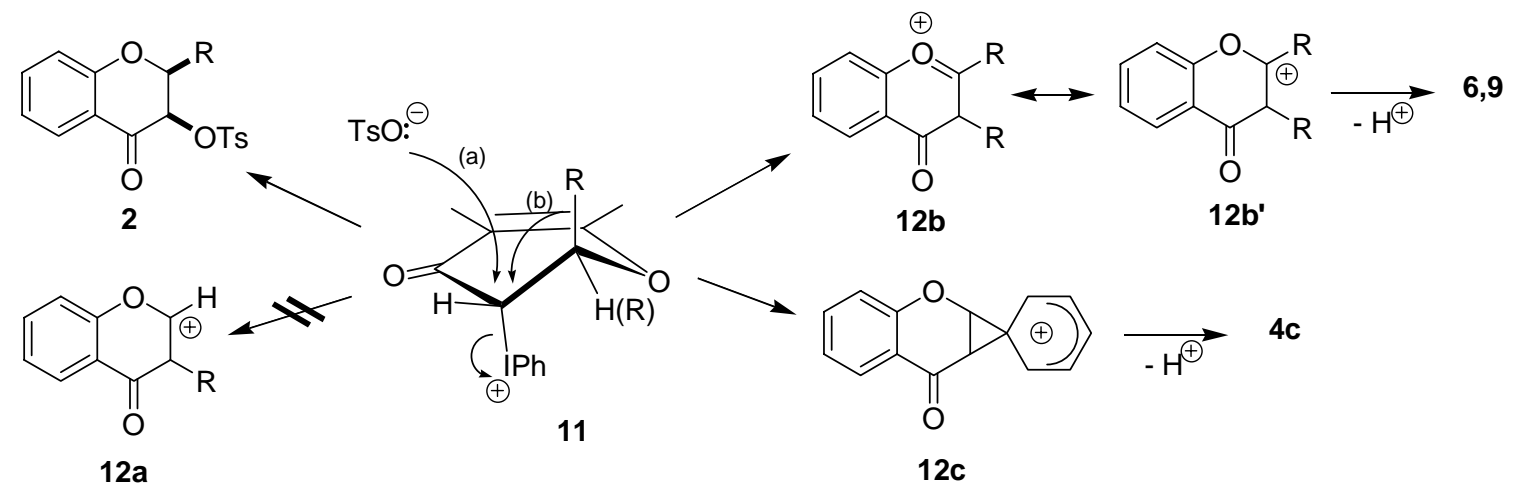

\section{Scheme 2}

The lack of an electron-donating 2-alkyl substituent in cation 12a makes it more unstable and hinders the migration in the case of 2-methylchromanone (1b). On the other hand, it seems very likely that the migration in the flavanone (1c) takes place via the phenonium intermediate 12c.

We have investigated also some heteroanalogs of chromanones. Treatment of 1thiochromanone 13a with HTIB under MW irradiation afforded the corresponding sulfoxide 14a, accompanied by a small amount of 1-thiochromone 15a. Surprisingly, the same product 14a was obtained in nearly the same yield without any MW activation simply by intimately mixing the reagents and the support. 2-Substituted-1-thiochromanones 13b,c gave similar results, affording the sulfoxides 14b,c with low-to moderate diastereoselectivity (Scheme 3, Table 4).<smiles>[R]c1cc(=O)c2ccccc2s1</smiles><smiles>O=C1CC(c2ccccc2)Nc2ccccc21</smiles>

16
17<smiles>[CH2]C(=O)N1c2ccccc2C(=O)CC1c1ccccc1</smiles>

18
19

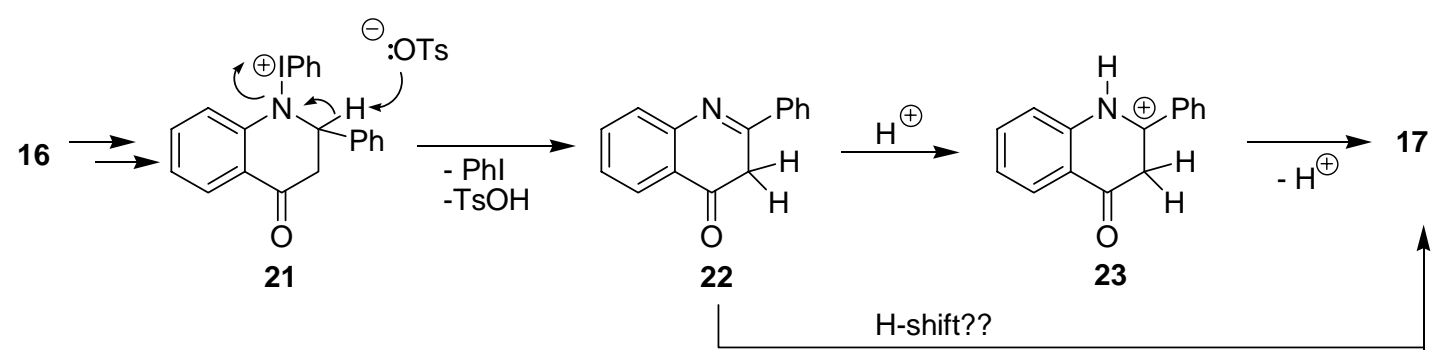

\section{Scheme 3}


Oxidation of sulfides to sulfoxides without apparent overoxidation to sulfones by [methoxy(tosyloxy)iodo]benzene (MTIB), obtained from HTIB and trimethyl orthoformate, ${ }^{23}$ or by HTIB or HCIB in methylene chloride, ${ }^{24}$ or by in situ generated HTIB in acetonitrile ${ }^{25}$ has been reported, but this is the first case where a heterogenous, solid-phase reaction has been observed. Our finding offers a new and easy entry to heterocyclic sulfoxides.

Table 4. Reaction of thiochromanones 13a-c and dihydroquinolones 16,18 with HTIB under MW irradiation using $\mathrm{Na}_{2} \mathrm{SO}_{4}$ support

\begin{tabular}{ccccccccc}
\hline Entry & $\begin{array}{c}\text { Starting } \\
\text { material }\end{array}$ & $\begin{array}{c}\text { HTIB } \\
\text { (equiv.) }\end{array}$ & $\begin{array}{c}\text { MW irradiation } \\
(\mathrm{min})\end{array}$ & Eluent $^{\mathrm{a}}$ & $\begin{array}{c}\text { Conversion }^{\mathrm{b}} \\
(\%)\end{array}$ & \multicolumn{3}{c}{ Yield $^{\mathrm{c}}(\%)$} \\
\hline 1 & $\mathbf{1 3 a}$ & 1.2 & $2 \mathrm{x} 1$ & $\mathrm{E}$ & 84 & $39(-)$ & 11 & - \\
2 & & 2.4 & $2 \times 1$ & $\mathrm{E}$ & 100 & $12(-)$ & 9.9 & - \\
3 & & 2.4 & none & $\mathrm{E}$ & 95 & $37(-)$ & traces & - \\
4 & $\mathbf{1 3 b}$ & 2.4 & none & $\mathrm{F}$ & 100 & $38(79: 21)$ & 9.1 & - \\
5 & $\mathbf{1 3 c}$ & 2.4 & none & $\mathrm{F}$ & 56 & $66(59: 41)$ & traces & - \\
6 & $\mathbf{1 6}$ & 2.4 & $2 \mathrm{x} 1$ & $\mathrm{E}$ & 55 & - & 12 & - \\
7 & $\mathbf{1 8}$ & 2.4 & $3 \times 1$ & $\mathrm{G}$ & 74 & - & - & $\mathbf{1 9 :} 15$ \\
\hline
\end{tabular}

${ }^{a}$ E: ethyl acetate, F: toluene-ethyl acetate $(4: 1, v / v)$, G: ethyl acetate-hexane $(8: 1, v / v)$

${ }^{\mathrm{b}}$ Calculated on the basis of the recovered starting material. ${ }^{\mathrm{c}}$ Refers to pure isolated products, the values are normalized to $100 \%$ conversion.

Finally, the reactivity of 2,3-dihydro-4-quinonolones 16, 18 was tested since previously very little had been published on the reaction of dihydroquinolones with hypervalent iodine reagents. 2-Aryl-2,3-dihydro-4-quinolones were reported to afford 4-alkoxy-2-arylquinolines in the presence of HTIB, trialkyl orthoformate and perchloric $\operatorname{acid}^{26}$ and 2-aryl-4-quinolones upon treatment with iodobenzene diacetate and potassium hydroxide in methanolic solution. ${ }^{27}$ Under our conditions, both substrates reacted sluggishly and low conversions were found even by using higher amounts of HTIB. The substitution on the nitrogen plays a decisive role since 2-phenyl2,3-dihydro-4-quinolone (16) gave the dehydrogenated 2-phenyl-4-quinolone (17) as the sole product while 1-acetyl-2-phenyl-2,3-dihydro-4-quinolone (18) yielded the migrated 3-phenyl-4quinolone (19) (Scheme 3, Table 4). Neither of these reactions has considerable synthetic value but each provides important mechanistic information. Similarly to the sulfur-containing substrates where the sulfoxidation proceeds by an electrophilic attack on the sulfur atom and runs via the intermediate 20, HTIB attacks the nucleophilic nitrogen atom in the dihydroquinolone $\mathbf{1 6}$ giving the phenyliodonium intermediate 21 and then finally the quinolone 22. This latter intermediate transforms into the final product, either by a hydrogen shift or by a protonationdeprotonation sequence (Scheme 3). The acylation of the nitrogen in compound 18 stops its nucleophilic character and directs the transformation to the enol mechanism shown in Scheme 2. This duality proves for the higher reactivity of nucleophilic heteroatoms toward HTIB in comparison with double bonds. 
In conclusion, the reaction of 2-unsubstituted and 2-alkylchromanones with HTIB was found to give the corresponding, hitherto unknown 3-tosyloxy derivatives, in addition to dehydrogenation, whereas dehydrogenation and/or 2,3-migration was observed with other chromanones. Attack at the nucleophilic heteroatom was observed in the reactions of 1thiochromanones or 2-phenyl-2,3-dihydro-4-quinolone, giving the corresponding sulfoxides or the dehydrogenated product, respectively.

\section{Experimental Section}

General Procedures. Column chromatography was performed on Kieselgel 60 or Kieselgel 40. - Melting points: Boetius hot-stage, uncorrected values. - IR: Perkin Elmer 16 PC-FT-IR; KBr pellets unless otherwise stated. - NMR: Bruker WP 200 SY, Bruker AM 360 (200 or $360 \mathrm{MHz}$ for ${ }^{1} \mathrm{H}$; 50 or $90 \mathrm{MHz}$ for ${ }^{13} \mathrm{C}$ ). Recorded in $\mathrm{CDCl}_{3}$ solution unless otherwise stated. Chemical shifts are given in $\delta$ relative to an internal standard TMS $(\delta=0)$ or to the residual $\mathrm{CHCl}_{3}(\delta=$ 7.26 for ${ }^{1} \mathrm{H}$ NMR and $\delta=77.0$ for ${ }^{13} \mathrm{C}$ NMR). - Elemental analysis: Carlo Erba EA $1106 \mathrm{CHN}$ analyzer. Starting materials 1a and 13a were purchased while 1b,c, 5a-g, 8a-c, 16 and 18 were synthesized according to literature methods.

\section{General procedure for the microwave-induced reactions}

Benzoheteracyclanone 1a-c, 5a-c,e-g, 8a-c, 16, or 18 (1 mmol), HTIB (1.2 or $2.4 \mathrm{mmol})$ and anhydrous sodium sulfate $(5 \mathrm{~g})$ were mixed thoroughly and irradiated in a household microwave oven $(2.45 \mathrm{GHz}, 700 \mathrm{~W})$ with a one-minute break between two exposures (for details see Tables $1-4)$. The mixture was washed with dichloromethane $(4 \times 30 \mathrm{~mL})$, concentrated in vacuo and the residue was submitted to short-column chromatography. Conversion and yields are shown in the Tables. Known products 3a-c, 4c were identified by TLC comparison, m.p. and ${ }^{1} \mathrm{H}$ NMR spectra. 3-Tosyloxychromanone (2a). For the conditions see Table 2. Mp 125-128 ${ }^{\circ} \mathrm{C}$ (hexane-EtOAc). IR: $1690(\mathrm{C}=\mathrm{O}), 1606,1478,1466,1364\left(\mathrm{SO}_{2}\right), 1314,1218,1192,1174\left(\mathrm{SO}_{2}\right), 1008,942,908$, 852, 814, 774, $738 \mathrm{~cm}^{-1} .{ }^{1} \mathrm{H}$ NMR: 2.48 (s, 3H, 4'-Me), 4.55 (dd, $J=10.0,11.0 \mathrm{~Hz}, 1 \mathrm{H}, 2-\mathrm{H}_{\mathrm{ax}}$ ), $4.66\left(\mathrm{dd}, J=5.1,11.0 \mathrm{~Hz}, 1 \mathrm{H}, 2-\mathrm{H}_{\mathrm{eq}}\right), 5.17$ (dd, $\left.J=5.1,10.0 \mathrm{~Hz}, 1 \mathrm{H}, 3-\mathrm{H}\right), 7.04$ (d, $J=8.4 \mathrm{~Hz}$, $1 \mathrm{H}, 8-\mathrm{H}), 7.11(\mathrm{~m}, 1 \mathrm{H}, 6-\mathrm{H}), 7.50\left(\mathrm{~d}, J=8.4 \mathrm{~Hz}, 2 \mathrm{H}, 3^{\prime}, 5^{\prime}-\mathrm{H}\right), 7.61(\mathrm{~m}, 1 \mathrm{H}, 7-\mathrm{H}), 7.75(\mathrm{~d}, J=9.0$ $\mathrm{Hz}, 1 \mathrm{H}, 5-\mathrm{H}), 7.90$ (d, $J=8.4 \mathrm{~Hz}, 1 \mathrm{H}, 2$ ', 6'-H). ${ }^{13} \mathrm{C}$ NMR: 21.6 (4'-Me), 69.8 (C-2), 75.5 (C-3), 118.7 (C-8), 122.9 (C-6), 128.1 (C-5), 129.0 (C-2',6'), 130.9 (C-3',5'), 134.2 (C-1'), 137.6 (C-7), 146.5 (C-4'), 162.0 (C-8a), 185.5 (C-4). Anal. Calcd. for $\mathrm{C}_{16} \mathrm{H}_{14} \mathrm{O}_{5} \mathrm{~S}$ (318.34): C, 60.37; H, 4.43. Found: C, 60.11; H, 4.59.

cis-2-Methyl-3-tosyloxychromanone (2b). For the conditions see Table 2. Mp 104-105 ${ }^{\circ} \mathrm{C}$ (hexane-abs. EtOH). IR: $1694(\mathrm{C}=\mathrm{O}), 1610,1466,1370,1364\left(\mathrm{SO}_{2}\right), 1312,1188,1178\left(\mathrm{SO}_{2}\right)$, 972, 948, 846, $684 \mathrm{~cm}^{-1} .{ }^{1} \mathrm{H}$ NMR: 1.50 (d, J=7.0 Hz, 3H, 2-Me), 2.45 (s, 3H, 4'-Me), 4.75 (m, $1 \mathrm{H}, 2-\mathrm{H}), 5.10(\mathrm{~d}, J=3.7 \mathrm{~Hz}, 1 \mathrm{H}, 3-\mathrm{H}), 6.96(\mathrm{~d}, J=8.4 \mathrm{~Hz}, 1 \mathrm{H}, 8-\mathrm{H}), 7.0$ (m, 1H, 6-H), 7.34 (d, $\left.J=8.4 \mathrm{~Hz}, 2 \mathrm{H}, 3^{\prime}, 5^{\prime}-\mathrm{H}\right), 7.50$ (m, 1H, 7-H, ), 7.72 (dd, $\left.J=1.8,8.0 \mathrm{~Hz}, 1 \mathrm{H}, 5-\mathrm{H}\right), 7.84$ (d, $J=8.4$ 
$\left.\mathrm{Hz}, 2 \mathrm{H}, 2^{\prime}, 6^{\prime}-\mathrm{H}\right) .{ }^{13} \mathrm{C}$ NMR: 14.5 (2-Me), 21.6 (4'-Me), 75.3 (C-3), 77.5 (C-2), 118.1 (C-8), 119.0 (C-4a), 121.8 (C-6), 127.3 (C-5), 128.0 (C-3',5'), 129.7 (C-3',5'), 133.0 (C-1'), 136.8 (C-7), 145.2 (C-4'), 159.8 (C-8a), 185.1 (C-4). Anal. Calcd. for $\mathrm{C}_{17} \mathrm{H}_{16} \mathrm{O}_{5} \mathrm{~S}$ (332.37): C, 61.43; H, 4.85. Found: C, 61.70; H, 4.69.

2,3-Dimethylchromone (6a). For the conditions see Table 3. Mp 93-94 ${ }^{\circ} \mathrm{C}$ (hexane) (Lit. ${ }^{28}$ 97$99{ }^{\circ} \mathrm{C}$, lit. $\left.{ }^{29} 91-93{ }^{\circ} \mathrm{C}\right)$. IR: $1632(\mathrm{C}=\mathrm{O}), 1609(\mathrm{C}=\mathrm{C}), 1470,1400,1173,772 \mathrm{~cm}^{-1} .{ }^{1} \mathrm{H}$ NMR: 2.06 (s, 3H, 2-Me), 2.42 (s, 3H, 3-Me), $7.32-7.39$ (m, 2H, 6,8-H), 7.60 (m, 1H, 7-H), 8.20 (dd, J = 1.3, 7.9 Hz, 1H, 5-H). ${ }^{13} \mathrm{C}$ NMR: 9.8 (3-Me), 18.3 (2-Me), 116.9 (C-3), 117.6 (C-8), 122.7 (C4a), 124.5, 125.9 (C-5, C-6), 133.0 (C-7), 156.0 (C-8a), 162.0 (C-2), 178.1 (C-4).

2,3-Dimethyl-7-methoxychromone (6b). For the conditions see Table 3. Mp 122-123 ${ }^{\circ} \mathrm{C}$ (hexane-EtOAc). (Lit. $\left.{ }^{30} 127^{\circ} \mathrm{C}\right)$. IR: $1640(\mathrm{C}=\mathrm{O}), 1618(\mathrm{C}=\mathrm{C}), 1604,1574,1442,1040,1352$, 1246 (C-O-C), 1204, $826 \mathrm{~cm}^{-1} .{ }^{1} \mathrm{H}$ NMR: 2.03 (s, 3H, 2-Me), 2.37 (s, 3H, 3-Me), 3.87 (s, 3H, 7OMe), $6.75(\mathrm{~d}, J=1.3 \mathrm{~Hz}, 1 \mathrm{H}, 8-\mathrm{H}), 6.91(\mathrm{dd}, J=1.3,9.6 \mathrm{~Hz}, 1 \mathrm{H}, 6-\mathrm{H}), 8.09$ (d, $J=9.6 \mathrm{~Hz}, 1 \mathrm{H}$, 5-H). ${ }^{13} \mathrm{C}$ NMR: 9.9 (3-Me), 18.4 (2-Me), 55.6 (7-OMe), 99.6 (C-8), 113.8 (C-6), 116.4 (C-3), 127.1 (C-5), 157.4 (C-8a), 161.2 (C-2), 163.4 (C-7), 177.3 (C-4).

7-Benzyloxy-2,3-dimethylchromone (6c). For the conditions see Table 3. Mp 92.5-93.5 ${ }^{\circ} \mathrm{C}$ (hexane). IR: $1644(\mathrm{C}=\mathrm{O}), 1610(\mathrm{C}=\mathrm{C}), 1442,1398,1344,1244$ (C-O-C), 1182, 1098, 746, $708 \mathrm{~cm}^{-1} .{ }^{1} \mathrm{H}$ NMR: 2.02 (s, 3H, 2-Me), 2.36 (s, 3H, 3-Me), 5.12 (s, 2H, $\left.\mathrm{CH}_{2}\right), 6.83$ (d, J=1.3 $\mathrm{Hz}, 1 \mathrm{H}, 8-\mathrm{H}), 6.99$ (dd, $J=1.3,8.3 \mathrm{~Hz}, 1 \mathrm{H}, 6-\mathrm{H}), 7.34-7.45$ (m, 5H, Ph), 8.09 (d, $J=8.3 \mathrm{~Hz}, 1 \mathrm{H}$, 5-H). ${ }^{13} \mathrm{C}$ NMR: 9.9 (3-Me), 18.4 (2-Me), $70.4\left(\mathrm{CH}_{2}\right), 100.8(\mathrm{C}-8), 114.3(\mathrm{C}-6), 116.5,116.8(\mathrm{C}-$ 3, C-4a), 127.3, 127.5, 128.3, 128.7 (C-5, C-2',6', C-3',5', C-4'), 135.9 (C-1'), 157.4 (C-8a), 161.2 (C-2), 162.5 (C-7), 177.3 (C-4). Anal. Calcd. for $\mathrm{C}_{18} \mathrm{H}_{16} \mathrm{O}_{3}$ (280.32): C, 77.12; H, 5.75. Found: C, 76.89; H, 5.94.

2,3-Dimethyl-7-tosyloxychromone (6e). For the conditions see Table 3. Mp 109-110 ${ }^{\circ} \mathrm{C}$ (hexane-EtOAc). IR: $1636(\mathrm{C}=\mathrm{O}), 1612(\mathrm{C}=\mathrm{C}), 1444,1376\left(\mathrm{SO}_{2}\right), 1192,1174\left(\mathrm{SO}_{2}\right), 1092,868$, 822, 814, $734 \mathrm{~cm}^{-1} .{ }^{1} \mathrm{H}$ NMR: 2.04 (s, 3H, 2-Me), 2.40 (s, 3H, 3-Me), 2.46 (s, 3H, 4'-Me), 6.85 $(\mathrm{dd}, J=2.1,8.8 \mathrm{~Hz}, 1 \mathrm{H}, 6-\mathrm{H}), 7.22(\mathrm{~d}, J=2.1 \mathrm{~Hz}, 1 \mathrm{H}, 8-\mathrm{H}), 7.33$ (d, $\left.J=8.0 \mathrm{~Hz}, 2 \mathrm{H}, 3^{\prime}, 5^{\prime}-\mathrm{H}\right)$, $7.73\left(\mathrm{~d}, J=8.0 \mathrm{~Hz}, 2 \mathrm{H}, 2^{\prime}, 6^{\prime}-\mathrm{H}\right), 8.08$ (d, $\left.J=8.8 \mathrm{~Hz}, 1 \mathrm{H}, 5-\mathrm{H}\right) .{ }^{13} \mathrm{C}$ NMR: 9.8 (3-Me), 18.3 (2Me), 21.6 (4'-Me), 111.7 (C-8), 117.4 (C-3), 119.0 (C-6), 121.4 (C-4a), 127.7 (C-5), 128.6 (C2',6'), 130.1 (C-3',5'), 132.1 (C-1'), 146.1 (C-4'), 152.7 (C-7), 156.2 (C-8a), 162.6 (C-2), 177.3 (C-4). Anal. Calcd. for $\mathrm{C}_{18} \mathrm{H}_{16} \mathrm{O}_{5} \mathrm{~S}$ (344.38): C, 62.78; H, 4.68. Found: C, 62.99; H, 4.88.

2,3-Dimethyl-6,7-ditosyloxychromone (6f). For the conditions see Table 3. Mp 166-169 ${ }^{\circ} \mathrm{C}$ (EtOH). IR: $1646(\mathrm{C}=\mathrm{O}), 1617(\mathrm{C}=\mathrm{C}), 1478,1448,1381\left(\mathrm{SO}_{2}\right), 1356,1194,1179\left(\mathrm{SO}_{2}\right), 1084$, 830, 817, 734, 706, $694 \mathrm{~cm}^{-1} .{ }^{1} \mathrm{H}$ NMR: 2.02 (s, 3H, 2-Me), 2.38 (s, 3H, 3-Me), 2.45, 2.46 (2xs,

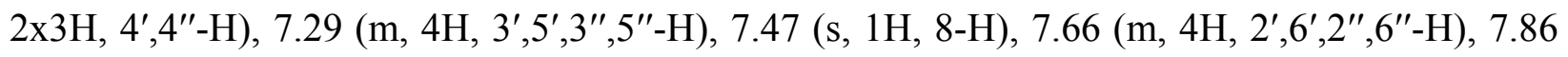
(s, 1H, 5-H). ${ }^{13} \mathrm{C}$ NMR: 9.8 (3-Me), 18.3 (2-Me), 21.6 (4', 4"-Me), 113.8 (C-8), 117.4 (C-3), 120.8 (C-6), 121.5 (C-4a), 128.7, 128.8 (C-5, C-2',6', C-2", 6"'), 130.0 (C-3',5', C-3", 5"), 131.9, $132.4\left(\mathrm{C}-1, \mathrm{C}-1^{\prime}\right), 138.5(\mathrm{C}-6)^{*}, 145.1$ (C-7)*, 146.1, 146.4 (C-4', C-4"), 153.9 (C-8a), 162.8 (C2), 176.4 (C-4). [*interchangeable] Anal. Calcd. for $\mathrm{C}_{25} \mathrm{H}_{22} \mathrm{O}_{8} \mathrm{~S}_{2}$ (514.56): C, 58.36; H, 4.31 . Found: C, 58.12; H, 4.37. 
7-Benzyloxy-2,3,5-trimethylchromone (6g). For the conditions see Table 3. Mp 108-112 ${ }^{\circ} \mathrm{C}$ (hexane-EtOAc). IR: $1654(\mathrm{C}=\mathrm{O}), 1612(\mathrm{C}=\mathrm{C}), 1570,1454,1280,1180,1156,756 \mathrm{~cm}^{-1} .{ }^{1} \mathrm{H}$ NMR: 1.98 (s, 3H, 2-Me), 2.32 (s, 3H, 3-Me), 2.82 (s, 3H, 5-Me), 5.10 (s, 2H, CH 2$), 6.69$ (d, J= $1.2 \mathrm{~Hz}, 1 \mathrm{H}, 8-\mathrm{H}), 6.74$ (br s, 1H, 6-H), 7.32-7.45 (m, 5-H, Ph). ${ }^{13} \mathrm{C}$ NMR: 10.0 (3-Me), 18.1 (2$\mathrm{Me}), 23.1$ (5-Me), $70.1\left(\mathrm{CH}_{2}\right), 98.9$ (C-8), 115.4, 117.2 (C-3, C-4a), 116.4 (C-6), 127.5, 128.7 (C-2',6', C-3',5'), 128.2 (C-4'), 136.1 (C-1'), 142.5 (C-5), 158.9 (C-8a), 159.4 (C-2), 161.1 (C7), 179.3 (C-4). Anal. Calcd. for $\mathrm{C}_{19} \mathrm{H}_{18} \mathrm{O}_{3}$ (294.35): C, 77.53; H, 6.16. Found: C, 77.72; H, 5.98. 2,3-Dimethyl-7-hydroxychromone (6d). A mixture of 7-benzyloxy-2,3-dimethylchromone (6c) [280 $\mathrm{mg}, 0.999 \mathrm{mmol}$ ], 48\% hydrogen bromide $(3 \mathrm{~mL})$ and acetic acid $(6 \mathrm{~mL})$ was refluxed for $15 \mathrm{~min}$, then poured on crushed ice, filtered off and washed with water to give pure 6d. Mp 268$271{ }^{\circ} \mathrm{C}(\mathrm{EtOH})$. IR: $3208(\mathrm{OH}), 1632(\mathrm{C}=\mathrm{O}), 1592,1570,1406,1246(\mathrm{C}-\mathrm{O}), 1188,1102,862 \mathrm{~cm}^{-1}$. ${ }^{1} \mathrm{H}$ NMR (DMSO-d 6 ): 1.90 (s, 3H, 2-Me), 2.35 (s, 3H, 3-Me), 6.76 (d, J=1.1 Hz, 1H, 8-H), 6.87 $(\mathrm{dd}, J=1.1,8.6 \mathrm{~Hz}, 1 \mathrm{H}, 6-\mathrm{H}), 7.85$ (d, $J=8.6 \mathrm{~Hz}, 1 \mathrm{H}, 5-\mathrm{H}), 10.64$ (s, 1H, 7-OH). ${ }^{13} \mathrm{C}$ NMR (DMSO-d 6 ): 10.6 (3-Me), 19.0 (2-Me), 102.6 (C-8), 115.4 (C-6), 115.8, 116.1 (C-3, C-4a), 127.7 (C-5), 158.0 (C-8a), 162.2, 163.0 (C-2, C-7), 176.8 (C-4). Anal. Calcd. for $\mathrm{C}_{11} \mathrm{H}_{10} \mathrm{O}_{3}$ (190.19): C, 69.46; H, 5.30. Found: C, 69.67; H, 5.25.

1,2,3,4-Tetrahydroxanthen-9-one (9a). For the conditions see Table 3. Mp 100-100.5 ${ }^{\circ} \mathrm{C}$ (hexane). (Lit. $\left.{ }^{16} 88-89{ }^{\circ} \mathrm{C}\right)$. IR: $2946\left(\mathrm{CH}_{2}\right), 1640(\mathrm{C}=\mathrm{O}), 1622(\mathrm{C}=\mathrm{C}), 1570,1474,1464,1424$, 1410, 1156, $768 \mathrm{~cm}^{-1} .{ }^{1} \mathrm{H}$ NMR: 1.74, $1.86(2 \mathrm{xm}, 2 \mathrm{x} 2 \mathrm{H}, 2,3-\mathrm{H}), 2.56,2.63(2 \mathrm{xt}, J=6.2 \mathrm{~Hz}$ and 6.4, 2x2H), 1,4-H), $7.21(\mathrm{~m}, 2 \mathrm{H}, 5,7-\mathrm{H}), 7.57(\mathrm{~m}, 1 \mathrm{H}, 6-\mathrm{H}), 8.17(\mathrm{dd}, J=1.2,7.9 \mathrm{~Hz}) .{ }^{13} \mathrm{C}$ NMR: 21.0, 21.6, 21.9 (C-2,3,4), 28.1 (C-1), 117.6 (C-5), 118.4 (C-9a), 123.1 (C-8a), 124.3, 125.7 (C7,8), 132.9 (C-6), 155.9 (C-5a), 163.9 (C-10a), 177.6 (C-9).

7,8,9,10-Tetrahydrobenzo[b]cyclohepta[e]pyran-11(6H)-one (9b). For the conditions see Table 3. Mp 79-80.5 ${ }^{\circ} \mathrm{C}$ (hexane). (Lit. $\left.{ }^{16} 82-83{ }^{\circ} \mathrm{C}\right)$. IR: $2924\left(\mathrm{CH}_{2}\right), 1632(\mathrm{C}=\mathrm{O}+\mathrm{C}=\mathrm{C}), 1608$, 1574, 1466, 1446, 1402, 1322, 1158, $762 \mathrm{~cm}^{-1} .{ }^{1} \mathrm{H}$ NMR: 1.61 (m, 2H, 8-H), 1.75, 1.84 (2xm, $2 \times 2 \mathrm{H}, 7,9-\mathrm{H}), 2.80,2.87(2 \times m, 2 \times 2 \mathrm{H}, 6,10-\mathrm{H}), 7.32-7.40$ (overlapping dd and $\mathrm{m}, 2 \mathrm{H}, 2,4-\mathrm{H}$ ), $7.61(\mathrm{~m}, 1 \mathrm{H}, 3-\mathrm{H}), 8.22(\mathrm{dd}, J=1.5,7.9 \mathrm{~Hz}, 1 \mathrm{H}, 1-\mathrm{H}) .{ }^{13} \mathrm{C}$ NMR: 22.11, 24.74, 26.22, 31.8, 34.6 (C-6,7,8,9,10), 117.6 (C-4), 122.6, 122.8 (C-10a,11a), 124.3 (C-1), 125.81 (C-2), 132.6 (C-3), 155.5 (C-4a), 168.8 (C-5a), 176.8 (C-11).

6,7,8,9,10,11-Hexahydrobenzo[b]cycloocta[e]pyran-12(6H)-one (9c). For the conditions see Table 3. Mp 87-89 ${ }^{\circ} \mathrm{C}$ (hexane). (Lit. $\left.{ }^{16} 90-91{ }^{\circ} \mathrm{C}\right)$. IR: $2930\left(\mathrm{CH}_{2}\right), 1632(\mathrm{C}=\mathrm{O}+\mathrm{C}=\mathrm{C}), 1612$, 1574, 1466, 1456, 1400, 1334, 1224, 1188, 1128, 780, $764 \mathrm{~cm}^{-1} .{ }^{1} \mathrm{H}$ NMR: 1.50 (m, 4H, 8,9-H), 1.72, $1.84(2 \mathrm{xm}, 2 \times 2 \mathrm{H}, 7,10-\mathrm{H}), 2.73,2.81(2 \mathrm{xt}, J=6.0 \mathrm{~Hz}, 2 \times 2 \mathrm{H}, 6,11-\mathrm{H}), 7.33-7.41$ (overlapping dd and $\mathrm{m}, 2 \mathrm{H}, 2,4-\mathrm{H}), 7.61(\mathrm{~m}, 1 \mathrm{H}, 3-\mathrm{H}), 8.21(\mathrm{dd}, J=0.9,8.1 \mathrm{~Hz}, 1 \mathrm{H}, 1-\mathrm{H}) .{ }^{13} \mathrm{C}$ NMR: 22.6, 26.0, 26.1, 28.8, 29.0, 31.2 (C-6,7,8,9,10,11), 117.6 (C-4), 120.4, 122.8 (C-11a,12a), 124.2 (C-1), 125.6 (C-2), 132.6 (C-3), 155.9 (C-4a), 166.1 (C-5a), 176.8 (C-12).

2-Phenyl-4-quinolone (17). For the conditions see Table 4. Mp 245-250 ${ }^{\circ} \mathrm{C}(\mathrm{MeOH})$. (Lit. ${ }^{31}$ 252-254 $\left.{ }^{\circ} \mathrm{C}\right)$. IR: $3432(\mathrm{NH}), 3064,2964,1632(\mathrm{C}=\mathrm{O}+\mathrm{C}=\mathrm{C}), 1580,1546,1504,1472,1450$, 1432, 1256, 1140, $770 \mathrm{~cm}^{-1} .{ }^{1} \mathrm{H}$ NMR (DMSO-d 6 ): 6.38 (s, 1H, 3-H), 7.40 (m, 1H, 6-H), 7.62 (m, 3H, 3',4',5'-H), $7.71(\mathrm{~m}, 1 \mathrm{H}, 7-\mathrm{H}), 7.81$ (d, $J=8.3 \mathrm{~Hz}, 1 \mathrm{H}, 8-\mathrm{H}), 7.88$ (m, 2H, 2',6'-H), 8.14 
$(\mathrm{d}, J=7.8 \mathrm{~Hz}, 1 \mathrm{H}, 5-\mathrm{H}), 11.77(\mathrm{~s}, 1 \mathrm{H}, \mathrm{NH}) .{ }^{13} \mathrm{C}$ NMR (DMSO-d $): 107.3(\mathrm{C}-3), 117.8(\mathrm{C}-8)$, 123.1 (C-6), 124.6 (C-4'), 127.3 (C-2',6'), 128.9 (C-3',5'), 129.6 (C-2), 130.3 (C-5), 131.7 (C-7), 134.2 (C-4a), 140.4 (C-8a), 150.8 (C-1'), 176.8 (C-4).

3-Phenyl-4-quinolone (19). For the conditions see Table 4. Mp 250-253 ${ }^{\circ} \mathrm{C}(\mathrm{MeOH})$. (Lit. ${ }^{32}$ 255-257 ${ }^{\circ} \mathrm{C}$, Lit. $\left.{ }^{33} 268-269{ }^{\circ} \mathrm{C}\right) .{ }^{1} \mathrm{H}$ NMR (DMSO-d $)$ ) 7.33 (m, 1H, 6-H), 7.39-7.45 (m, 3H, 3', 4',5'-H), 7.63 (d, $J=8.0 \mathrm{~Hz}, 1 \mathrm{H}, 8-\mathrm{H}), 7.71$ (m, 1H, 7-H), 7.77 (dd, $J=1.1,7.3 \mathrm{~Hz}, 1 \mathrm{H}, 2^{\prime}, 6$ 'H), $8.20(\mathrm{~d}, J=6.2 \mathrm{~Hz}, 1 \mathrm{H}, 2-\mathrm{H}), 8.23(\mathrm{~d}, J=7.9 \mathrm{~Hz}, 1 \mathrm{H}, 5-\mathrm{H}), 12.11(\mathrm{~d}, J=6.2 \mathrm{~Hz}, 1 \mathrm{H}, \mathrm{NH})$. ${ }^{13} \mathrm{C}$ NMR (DMSO-d $)$ : 118.7 (C-8), 120.5 (C-3), 124.2, 126.1, 127.1 (C-5,6,4'), 126.1 (C-4a), 128.5, 129.0 (C-2',6', C-3',5'), 132.4 (C-7), 136.4 (C-1'), 138.7 (C-2), 139.6 (C-8a), 175.6 (C-4).

\section{Acknowledgements}

This work was supported financially by NATO (HTECH.LG 97.4558) and the Hungarian Scientific Research Fund (OTKA T22290). We thank Mr. I. Ócsai for some preliminary experiments.

\section{References}

1. (a) Neiland, O.; Karele, B. Zh. Org. Khim. 1970, 6, 885. (b) Koser, G. F. Wettach, R. H. J. Org. Chem. 1977, 42, 1476.

2. Selected reviews: (a) Moriarty, R. M.; Vaid, R. K.; Koser, G. F. Synlett 1990, 365. (b) Prakash, O.; Saini, N.; Sharma, P. K. Synlett 1994, 221. (c) Prakash, O.; Saini, N.; Sharma, P. K. Heterocycles 1994, 36, 409. (d) Prakash, O. Aldrichimica Acta 1995, 28, 63. (e) Moriarty, R. M.; Prakash, O. Adv. Heterocycl. Chem. 1998, 69, 1. (f) Koser, G. F. Aldrichimica Acta 2001, 34, 89.

3. (a) Kawamura, Y.; Maruyama, M.; Tokuoka, T.; Tsukayama, M. Synthesis 2002, 2490. (b) Kawamura, Y.; Maruyama, M.; Yamashita, K.; Tsukayama, M. Int. J. Mod. Phys. B. 2003, $17,1482$.

4. Xie, Y. Y.; Chen, Z. C.; Zhang, Q. G. J. Chem. Res. [S] 2002, 618.

5. Xie, Y. Y.; Chen, Z. C. Synth. Commun. 2002, 32, 1875.

6. Ueno, M.; Nabana, T.; Togo, H. J. Org. Chem. 2003, 68, 6424.

7. Lee, J. C.; Ku, C. H. Synlett 2002, 1679.

8. Selected reviews: (a) Caddick, S. Tetrahedron 1995, 51, 10403. (b) Strauss, C. R.; Trainor, R. W. Aust. J. Chem. 1995, 48, 1665. (c) Galema, S. A. Chem. Soc. Rev. 1997, 26, 233. (d) Loupy, A.; Petit, A.; Hamelin, J.; Texier-Boullet, F.; Jacqualt, P.; Mathe, D. Synthesis 1998, 1213. (e) Varma, R. S. Green Chemistry 1999, 43. (f) Varma, R. S. Pure Appl. Chem. 2001, 73, 193. (g) Varma, R. S. Organic Synthesis using Microwaves and Supported Reagents. In: Microwaves in Organic Synthesis, Loupy, A., Ed.; Wiley-VCH: Weinheim, 2002; p 181. (h) 
Varma, R. S. Advances in Green Chemistry: Chemical Synthesis using Microwave Irradiation. Astra Zeneca Research Foundation India: Bangalore, India, 2002 (free copy available from: azrefi@astrazeneca.com). (i) Varma, R. S. Tetrahedron 2002, 58, 1235.

9. Varma, R. S.; Kumar, D.; Liesen, P. J. J. Chem. Soc., Perkin Trans. 1 1998, 4093.

10. Kumar, D.; Singh, O. V.; Prakash, O.; Singh, S. P. Synth. Commun. 1994, 24, 2637.

11. Woydowski, K.; Ziemer, B.; Liebscher, J. J. Org. Chem. 1999, 64, 3489.

12. Patonay, T.; Hofman, R. V. J. Org. Chem. 1994, 59, 2902.

13. Prakash, O.; Pahuja, S.; Goyal, S.; Sawhney, S. N.; Moriarty, R. M. Synlett 1990, 337.

14. Prakash, O.; Pahuja, S.; Moriarty, R. M. Synth. Commun. 1990, 20, 1417.

15. (a) Singh, O. V.; Garg, C. P.; Kapoor, R. P. Tetrahedron Lett. 1990, 31, 2747. (b) Kinoshita, T.; Ichinose, K.; Sankawa, U. Tetrahedron Lett. 1990, 31, 7355. (c) Khanna, M. S.; Singh, O. V.; Garg, C. P.; Kapoor, R. P. J. Chem. Soc., Perkin Trans. 1. 1992, 2565. (d) Singh, O. V.; Kapil, R. S. Indian J. Chem. 1993, 32, 911.

16. Singh, O. V.; Kapil. R. S.; Garg, C. P.; Kapoor, R. P. Tetrahedron Lett. 1991, 32, 5619.

17. Adjangba, M. S. Bull. Soc. Chim. Fr. 1964, 376.

18. Hase, K.; Li, J.; Basnet, P.; Xiong, Q.; Takamura, S.; Namba, T.; Kadota, S. Chem. Pharm. Bull. 1997, 45, 1823.

19. Banerji, A.; Desphande, A. D.; Pradhan, P. Tetrahedron Lett. 1991, 32, 4995 and the references cited therein.

20. (a) Aida, M.; Yamaguchi, N.; Hano, Y.; Nomura, T. Heterocycles 1997, 45, 163. (b) Hakim, E. H.; Asnizar, Y.; Aimi, N.; Kitayama, M.; Takayama, H. Fitoterapia 2002, 73, 668.

21. Gabbutt, C. D.; Hepworth, J. D.; Heron, B. M.; Thomas, J.-L. Tetrahedron Lett. 1998, 39, 881.

22. ChemDraw3D ${ }^{\circledR}$ Ultra 1985-2003, CambridgeSoft Corp., Cambridge, MA 02140, USA; MOPAC calculation.

23. Koser, G. F.; Kokil, P. B.; Shah, M. Tetrahedron Lett. 1987, 28, 5431.

24. Xia, M.; Chen, Z.-C. Synth. Commun. 1997, 27, 1315.

25. Yang, R.-Y.; Dai, L.-X. Synth. Commun. 1994, 24, 2229.

26. Varma, R. S.; Kumar, D. Tetrahedron Lett. 1998, 39, 9113.

27. Prakash, O.; Kumar, D.; Saini, R. K.; Singh, S.P. Synth. Commun. 1994, 24, 2167.

28. Becket, G. J.; Ellis, G. P.; Trindade, M. I. U. J. Chem. Res. (S) 1978, 47; (M) 1978, 865.

29. Hirao, I.; Yamaguchi, M.; Hamada, M. Synthesis 1984, 1076.

30. Canter, J. J. Chem. Soc. 1931, 1255.

31. Kuo, S.-C.; Lee, H.-Z.; Juang, J.-P.; Lin, Y.-T.; Wu, T.-S.; Chang, J.-J.; Lednicer, D.; Paull, K. D.; Lin, C. M.; Hamel, E.; Lee, K.-H. J. Med. Chem. 1993, 36, 1146.

32. Tökés, A. L.; Antus, S. Liebigs Ann. Chem. 1993, 927.

33. Huang, L.-J.; Hsieh, M.-C.; Teng, C.-M.; Lee, K.-H.; Kuo, S.-C. Biorg. Med. Chem. 1998, $6,1657$. 